\title{
CULTURA VISUAL E HISTORIA DEL ARTE. LA PUESTA EN EVIDENCIA DE LOS ESTUDIOS VISUALES
}

\author{
Visual Culture and History of Art. The highlight of Visual Studies
}

Pierre Chateau*

\begin{abstract}
RESUMEN
En el presente artículo los Estudios Visuales son analizados como surgidos a partir de un ejercicio de autocrítica desde el interior de la disciplina de la Historia del Arte y como su propia puesta en evidencia en torno a sus categorías conceptuales y epistemológicas usuales. El observador, la inclusión de imágenes no artísticas, la visualidad y los propios conceptos centrales de la Estética y la Historia del Arte han sido puestos a prueba en la medida en que se ha vuelto sobre sus propios orígenes. El propósito es doble: comprenderlos y analizarlos en su real significado ateniéndose a su particularidad histórica del momento de creación y, junto a ello, la posibilidad de entender las imágenes como actos de pensamiento que cuestionan estas nociones conceptuales universales más allá de su especificidad espacial y temporal.
\end{abstract}

Palabras clave: Estudios visuales, Historia del Arte, cultura visual, imagen, autocrítica.

* PIIE, Pontificia Universidad Católica de Valparaíso. Valparaíso, Chile. Correo electrónico: pchateau@gmail.com

Artículo recibido el 01 de septiembre de 2014. Aceptado el 23 de septiembre de 2016. 


\begin{abstract}
In this investigation the Visual Studies are examined as arising from a self-criticism practice from within Art History discipline and also its own highlight about its conceptual and epistemological categories. The observer, the inclusion of non-artistic images, the visuality, and the central concepts of the Aesthetic and Art History have been put to the test, to the extent that it has been turn over to their own origins, with the aim of understanding them and analyzing them in their real meaning, according to their historical particularity, and, at the same time, the possibility that images can be conceived as thinking acts questioning these conceptual notions beyond their spatial and temporal specificity.
\end{abstract}

Keywords: Visual studies, History of Art, visual culture, imagen, self-criticism.

\title{
ORÍGENES OLVIDADOS
}

Desde el surgimiento de los Estudios Visuales el equilibrio disciplinar de la Historia del Arte se vio envuelto en las más ácidas críticas, defensas, acusaciones, burlas y detracciones. Reflejada sobre todo a partir de los años noventa, en la inclusión de un programa académico de Estudios Visuales en la Universidad de Rochester (1991) llevado a cabo, entre otros por William Jones Thomas Mitchell, resulta casi evidente que los Estudios Visuales iban en camino a convertirse en un área de estudio independiente más que en una metodología dentro de la Historia del Arte, de la que, sin embargo, surgió. La premisa básica de la importancia que se ha asignado a los Estudios Visuales radica en el "giro icónico» o pictorical turn que propusiera Keith Moxey, donde argumenta que tanto en el área de la antropología, ejemplificada en la escuela alemana de Hans Belting y Horst Bredekamp, como en la de los Estudios Visuales anglófonos de Mitchell y James Elkins, hubo -una vuelta hacia la imagen como algo activo y presente más allá de su particularidad y originalidad histórica (Moxey, 2009), y más allá de su "artisticidad".

Lejos de establecer su real significado, definición o campo de estudio ya bastante discutido (Alpers et al., 1996), lo que aquí se intenta es establecer sus orígenes primero como concepto y luego como campo de estudios insertándolo en la disciplina de la Historia del Arte de la cual surgió y de la que frecuentemente no se tiene en cuenta como parte integrante de su real significado e importancia. Junto a lo anterior, se busca también exponer cuál ha sido el lugar de la imagen en los Estudios Visuales en comparación a la Historia del Arte y las aportaciones de otras disciplinas como la Antropología del Arte y la Filosofía en la reordenación del campo de estudio de lo que se ha denominado como "lo visual".

Empecemos con la terminología, o aquello que Mitchell llama como “abordar las zonas grises”. Para este autor es útil distinguir desde un principio 
entre Estudios Visuales y Cultura Visual pues comúnmente se han empleado como sinónimos indistinta y confusamente. El primero es el campo de estudio y el segundo su objeto: de esta forma, Estudios Visuales son los estudios sobre la Cultura Visual, evitando la corriente confusión que se da en disciplinas como la Historia donde el campo de estudio y su objeto reciben el mismo nombre (Mitchell, 2003). Ahora bien, a la pregunta en qué consiste la Cultura Visual, podemos proponer que sus objetos no son tanto aquellos visuales sino la propia visualidad. Sin embargo, esta visión, en primera instancia "limpia" y transparente, es per se impura, pues se encuentra inherentemente delimitada y cargada de discursos y prácticas que la condicionan históricamente. En este sentido, en lugar de la visualidad como propiedad característica y definitoria de los objetos, son los actos de visión hacia los mismos los que deben constituir su objeto de dominio: su historicidad y su anclaje social son la condición de posibilidad del análisis desde la perspectiva de los Estudios Visuales (Bal, 2004). Desde este punto de vista, parece obvio que el término "Cultura Visual» haya sido expuesto por primera vez en un texto de Historia del Arte hecho por historiadores del Arte.

Para Bal, como consecuencia del entendimiento de la visualidad no como una cualidad de las cosas ni tampoco un mero fenómeno fisiológico, su estudio requiere el cuestionamiento de las nociones heredadas de "lo visual" y de "cultura" a partir de la propia óptica metodológica de los Estudios Visuales. Para el primer caso, puede servir una distinción básica entre los conceptos de lo visual y lo visivo: lo visual lo entendemos como un desarrollo mental a través del cual se procesan conceptos o significados a partir de lo percibido por medio del sentido de la vista. Lo visivo, por otro lado, es un proceso físico/fisiológico por medio del cual la luz impresiona los ojos y crea sensaciones visivas (García, 2009). El primero es mediado culturalmente, lo segundo no. Entendiendo de esta manera el campo de la visualidad, esta no solo corresponde al ámbito de las imágenes sobre las que se ha ocupado tradicionalmente la Historia del Arte (incluso con la salvedad de comprenderlas como imágenes mediatizadas por procesos extra-artísticos y por tanto como productos culturales) sino que el campo de estudio requiere, consecuentemente, una ampliación desde los objetos, artísticos o no, hacia el sujeto, los medios, las técnicas, el poder y sus relaciones.

Para el segundo caso, el de la re-definición de "cultura", es la propia Bal quien lanza los posibles parámetros para la re-significación del término. Este, para la autora, debiese ser re-situado, problemáticamente, entre lo global y lo local, manteniendo la especificidad de ambos, como entre "arte" y "cotidianeidad". Así expuesto, el concepto debiese entenderse como discursos y prácticas impuestas hegemónicamente, tanto como lugares de resistencia frente a la retórica dominante donde puedan desarrollarse, según la propia autora, códigos alternativos (Bal, 2004). 
Y fue frente a una hegemonía, la del Arte italiano, clásico y mediterráneo en el modo de apreciar y estudiar el arte europeo en general, lo que Svetlana Alpers se alzó en su ya clásico libro El arte de describir. Su llamado de atención sobre la diferencia que hay entre el arte holandés y el mediterráneo del siglo XVII no es solo aplicable para aquellos que dedican sus investigaciones al estudio del arte holandés como para cualquiera que se interese por el estudio del arte, en cualquiera de sus niveles (Alpers, 1987). La advertencia, y la crítica que va de la mano, es a toda la estructura historiográfica construida sobre supuestos hegemónicos que pretende, o pretendía, dominar todo el estudio de las imágenes occidentales reduciéndolas a un patrón epistemológico y retórico común, que podríamos denominar clasicista. La respuesta de Alpers fue entender las imágenes holandesas como una retórica de resistencia a este discurso dominante: una Cultura Visual propia. Este término, entonces, debe ser entendido como un perfecto ejemplo de aquello que Bal denominó como la problemática posición del término «cultura» entre lo local y lo global.

Si Alpers fue la primera en ubicar el concepto de Cultura Visual como el centro de su análisis, el término ya había sido usado por otro investigador con el que trabajó posteriormente en la redacción de un libro, el historiador británico del arte Michael Baxandall (Alpers y Baxandall, 1994). Por esta razón es, quizás, que frecuente y generalmente los Estudios Visuales sean tratados como parte y extensión de la Historia Social del Arte, campo al que se dedicaba el británico. Esto último supone un gran problema en la comprensión de los Estudios Visuales, puesto que, la Historia Social del Arte a pesar de su enfoque más amplio del proceso artístico, no cuestiona la categoría tradicional de arte heredada de la estética y la historiografía más tradicional.

Ante este panorama, se ha acusado a los Estudios Visuales de no tener un objeto de análisis bien definido, un campo de estudios acotado ni una metodología fundamentada, precisa y concreta. De ahí, por ejemplo, el intento de Bal, que hemos tomado aquí, de esclarecer y delimitar el término de Cultura Visual. Y, si extendemos este planteamiento sin intentar agotar en esta empresa la variedad del campo de estudio que proponen los Estudios Visuales, en lugar de perseguir un objetivo de carácter enciclopédico estos han de aceptar su estatus cambiante y provisional, dada la constante formación (y reformulación) de los medios visuales contemporáneos y de sus usos y apropiaciones (Hernández, 2005).

Esto pone de manifiesto que los Estudios Visuales van de la mano con las prácticas visuales de la contemporaneidad. ¿Cómo, en efecto, no van a ser heterogéneos, provisionales y cambiantes si, en su propio tiempo de formación como campo de estudio, todas las manifestaciones culturales (en específico las visuales) apuntan justamente a eso? Muy distinto es, por ejemplo, al tiempo de formación de otras metodologías de estudio de las imágenes como el formalismo 
de Heinrich Wölfflin, la iconología de Erwin Panofsky e incluso la sociología del arte de Arnold Hauser y su cada vez mayor incorporación de elementos extraartísticos al estudio de las imágenes. En este sentido, la historiografía del arte puede resumirse en una dialéctica de una línea "contextual», ejemplificada en Baxandall y Panofsky opuesta a una "autónoma» con exponentes como Wölfflin, Alois Riegl y Clement Greenberg, las cuales perpetuaron el apogeo de la iconología en la que lo último que se esperaba del historiador era la expresión subjetiva de su experiencia estética (Moxey, 2006), y no cuestionaron la posible existencia o construcción de uno o varios meta-relatos omnicomprensivos y totalizantes, sino que incluso todos aspiraron a convertirse en uno de ellos.

¿Será que los Estudios Visuales representan la renuncia, aun implícita, hacia una o cualquiera pretensión de cientificidad absoluta en el estudio de las imágenes? Parece que luego del libro de Thomas Kuhn La estructura de la revoluciones cientificas (1972), y su reflexión en torno a la institución de la(s) ciencia(s) donde demuestra que los paradigmas de las ciencias físicas y naturales son producto, entre otros factores, de un consenso dentro de la institución, resulta obvio y necesario que cualquier disciplina deba mirarse a sí misma en un ejercicio autocrítico donde cualquier pretensión de absoluto cientificismo, sobre todo en un área como la Historia del Arte que lo ha anhelado constantemente, debiese ser al menos examinada.

Desde este punto de vista los Estudios Visuales son el positivo resultado del ejercicio de autocrítica desde dentro de la Historia del Arte y que involucra a otros campos de conocimiento como la filosofía, antropología, estética, lingüística, semiología, teoría crítica, estudios de género y estudios postcoloniales, con la constante y coherente renuncia desde los Estudios Visuales hacia cualquier pretensión de construcción de un meta-relato omniexplicativo del mundo de lo visual, considerándose como una más de las muchas explicaciones que enriquezca lo ya aportado por esas otras disciplinas en general y la Historia del Arte, de la que surge, en particular. De ahí su consecuente apertura hacia otras categorías no tradicionales de estudio (como el observador, el aparato, la superficie y los discursos) y sobre todo la ampliación del espectro de lo artístico hacia lo visual conscientes que el valor artístico es un ańadido posterior y consensuado que deja muchas manifestaciones visuales fuera de los tradicionales campos de estudio. Esta no pretensión de exclusividad o de convertirse en paradigma, para adoptar la terminología de Kuhn, no catalogaría a los Estudios Visuales como una disciplina propiamente tal sino como una más entre muchas otras vías de estudio de la visualidad, carácter que extrapola a su propia práctica investigativa.

De esta forma las categorías del objeto y la metodología tan criticadas a los Estudios Visuales pueden tomar otro sentido y probar de paso que estos son una expresión de autocrítica que surgió desde la Historia del Arte y que se 
deben entender como un hacerse-ver y hacerse-saber sobre la propia retórica con la que ha sido construida esta disciplina. Dos visiones aportarán para esclarecer este punto. Stephen Melville escribió, en el cuestionario sobre Cultura Visual de la revista October de 1996 (Alpers et al., 1996), que no le parece evidente que los Estudios Visuales sean interdisciplinarios de forma que resulte interesante, pues la interdisciplina para él se produce cuando los Estudios Visuales sean una nueva configuración de métodos ya existentes para objetos ya identificados. Esta reflexión, sin embargo, solo tiene sentido si se tiene por objetos de estudio los objetos visuales, la materialidad per se. No obstante, como argumentamos, los objetos de los Estudios Visuales son las relaciones entre el que mira y lo mirado, sus articulaciones, discursos, funcionalidades y configuraciones donde la materialidad es solo uno de los aspectos del objeto de estudio que constituye la visualidad y no un objeto en sí mismo.

Paralelamente, sobre la metodología, tomemos como punto de partida la advertencia que lanzó Peter Leech sobre el futuro (ahora presente) de los Estudios Visuales, cuando escribió lo siguiente: "como todos los movimientos, los estudios visuales culturales pueden morir pronto. Su mortalidad se autoinscribe en sus fijaciones con lo sublime y con lo cultural como presente" (Leech, 2004, p. 6). Considerando lo ya expuesto, podemos afirmar que Leech no distingue entre una metodología anclada en el presente de un objeto anclado en el presente. Si fuese este último caso sería más probable que su profecía se cumpla, no obstante, en el primer caso su afirmación carece de sentido pues los Estudios Visuales son (o fueron) la innovación metodológica de su presente. No pueden entenderse, en su origen, sino como un ejercicio de autocrítica que abarca todas las esferas de la disciplina de la Historia del Arte. No hay que olvidar que el concepto de Cultura Visual proviene de un historiador del arte en un trabajo sobre Historia del Arte y desde hace ya más de treinta ańos en el caso de Alpers y cuarenta en el caso de Baxandall, tiempo más que suficiente para dejar su impronta en el mundo del conocimiento y la academia y configurarse como un tercer momento que otorgue la sensación de sentido y totalidad a esa dialéctica historiográfica antes expuesta.

\section{LO ARTÍSTICO Y EL LUGAR DE LA IMAGEN}

La preocupación por la construcción de un término como Cultura Visual como campo de análisis de los Estudios Visuales es debida tanto a una preocupación en torno a la metodología de la investigación histórica como a una inclusión de elementos epistemológicos y analíticos que tradicionalmente estuvieron fuera de las preocupaciones de la disciplina de la Historia del Arte. No obstante, puede argumentarse que esta última vino como consecuencia, a su vez, 
de una preocupación mayor: la inquietud cada vez más grande por el papel de las imágenes, museos y exposiciones en la reconstrucción de sentido en torno a las sociedades pasadas ejemplificadas en el "giro visual» o pictorical turn tomando la nomenclatura de Moxey (Palós, 2000). Sin embargo, también es patente la poca preparación metodológica y teórica de los historiadores a la hora de trabajar con imágenes como documentos históricos, la misma crítica que hiciese el historiador británico Peter Burke ańos antes (Burke, 2005).

Y llegado a este punto, parece que la crítica de los Estudios Visuales a la Historia y a la Historia del Arte tendría asidero, pues gran parte de los historiadores del arte como Arnold Hauser, que consideraron las imágenes como el reflejo de la estructura económica, política y social (Hauser, 2009), tomaron la imagen como ejemplo, como receptora de procesos mayores de carácter extra-artísticos: la imagen como mera ilustración de aquellas ideas que fueron planteadas sin necesidad, paradójicamente, de analizar la imagen. Una vez más, la imagen supeditada a la palabra. No obstante, la articulación de sentido en torno a la vida de las sociedades pasadas, la recreación de contextos culturales y sociales, no puede llevarse a cabo solo considerando las imágenes como reflejo de algo, sino que debe complementarse con lo que los sujetos hacen y construyen con esas imágenes.

De productores a consumidores, del autor al observador, es el giro más considerable que han puesto en el tapete los Estudios de la Cultura Visual, también sobre la base que no solamente son los sujetos (históricos) los que crean objetos, sino que son estos últimos los que producen sujetos. No existe el usuario antes del utensilio, y no olvidemos que las imágenes producidas hasta principios del siglo XIX no estaban hechas para el juicio estético desinteresado que propusiese Kant, sino que tenían un objetivo preciso; un espacio determinado (la iglesia o el palacio, no el museo ni el salón); y un público conocido (un círculo cerrado y no el observador desconocido y anónimo de la modernidad).

"Los aparatos modernos configuraron la sensibilidad común. En ese sentido, solo si seguimos esa aproximación podremos descubrir un hacer-mundo y un hacer-época” escribió Jean-Louis Déotte (Déotte, 2012, p. 12). El aparato es primero y luego viene la época, la Historia (entendida como elaboración posterior en constante construcción), puesta en escena por él. Solo así es posible, por ejemplo, la historia de la pintura renacentista: cuando el aparato perspectivo de Brunelleschi y Alberti entra en escena y configura una manera de ver, pintar, dibujar, discutir y escribir sobre pintura y arquitectura De ahí que no debamos establecer un conocimiento solo basado en la imagen como si esta fuera autónoma, independiente y a-histórica, sino que debe incluirse el aparato que la hizo posible, la superficie que la hace visible y el observador que le otorga sentido, tal como hiciese Jonathan Crary en su estudio sobre las técnicas del observador del siglo XIX (Crary, 2008). De este modo, la Cultura Visual como objeto de investigación 
de los Estudios Visuales se configura sobre el principio según el cual la visión y los objetos visuales son un medio a través del cual se transportan conceptos, ideas y nociones. En otras palabras, se pone en entredicho la categoría moderna de arte en tanto ha sido la única que merece ser objeto de estudio de una disciplina arraigada en el ámbito académico institucional y la imagen, en su más amplio sentido de la palabra, artística o no, se constituiría como su reemplazante objetual.

¿Debe entenderse entonces la Cultura Visual como la afirmación de la autonomía de lo visual respecto a su propio campo de estudio? Podemos afirmar que dentro determinadas sociedades avanzadas, en la óptica se produjo una primacía real de la imagen que logró sobreimponerse al texto escrito y constituirse en el elemento central de todas las praxis de la representación (De la Flor, 2007). Si extendemos este planteamiento, los Estudios de la Cultura Visual, alejándose de las metodologías que (im)ponían su acento en la literatura y el lenguaje, colocaron de manifiesto que aquellas imágenes que se correspondían con una estructura de significados y significantes, de signos y símbolos lingüísticos, fuesen consideradas las obras de arte dignas de análisis por parte de la Historia del Arte por sobre otros objetos visuales, algo que los Estudios de la Cultura Visual procurarían no realizar en su pretensión de incluir todo el espectro de imágenes como objeto de estudio. Así, puede que, por un lado, ataque la autonomía (entendida como hegemonía) del arte pero, por otro lado, y lo que debiese ser comprendido como su verdadero propósito disciplinar, provoca una autonomización de lo visual en su sentido más amplio, de objetos, prácticas y discursos, al liberarlo de la dependencia de la escritura como legitimadora de la imagen. Aquí se entiende la pertenencia, para la real comprensión del término de Cultura Visual y del propósito de los Estudios Visuales, del estudio de Alpers sobre el arte holandés del siglo XVII.

Si es problemático que esta autonomización de lo visual sea entendida por los críticos de los Estudios Visuales como una indefinición de lo que hasta ese momento se denominó como arte, su sentido como una ampliación es indiscutible. ¿Cómo no ampliar el método cuando se amplió el objeto que estudia? Una apertura del campo de las eventuales ciencias del arte viene exigida, en primer lugar, por la propia extensión de la forma de hacer del trabajo artístico y su desbordamiento de cualquier horizonte formal o material (Brea, 2006). El arte constituye solo "una parte del mar, pequeña por lo demás, dentro del imaginario colectivo donde se mueven las sociedades pasadas y presentes. Por esta misma razón, no hay motivos para seguir dedicando la atención hacia esa pequeña isla cuando está rodeada por un vasto océano visual" (Elkins, 1999, pp. 8-25). En este sentido, los Estudios Visuales no se proponen justamente diferenciar o separar al arte de las "meras" imágenes solo como una pataleta institucional en pos de autonomía disciplinar (incluso si esto último fuese cierto en un futuro próximo) frente a la Historia del Arte, sino que tratar el arte como fue pensado originalmente (en contextos pre- 
modernos), como una imagen, en su más amplio sentido de la palabra. De esta forma, en este retorno a lo original, la imagen vuelve a ser tal ya no con el epíteto moderno de obra, añadido posteriormente, y los Estudios Visuales se aproximan a ella sin el filtro posterior del estatus de obra artística. En otras palabras, existe una conciencia compartida en los Estudios Visuales según la cual las categorías absolutas de apreciación estética construidas en un momento histórico específico (fines del siglo XVIII) no necesariamente tienen validez universal y menos aun cuando el contexto y medios de creación, exposición, recepción, estudio y apreciación de los objetos visuales ha cambiado sustancialmente, como ocurrió a comienzos del siglo XX. La estética ha permitido que los artefactos visuales producidos en todo el mundo sean "equivalentes": proceso de normalización, despojador de sentido crítico que no puede seguir siendo ignorado.

Si tras la obra de Andy Warhol podemos referirnos a la supuesta desaparición de la distinción entre cultura de masas y arte elitista en nuestro tiempo, se confirma que los Estudios Visuales no proponen abolir el arte o su etiqueta, sino que hacerla, expresa y explícitamente, aquello que el concepto de arte entre otras cosas significa: una construcción posterior (otra de sus puestas en evidencia). Los Estudios Visuales solo se abren a otras imágenes como un modo de acercarse a ellas en su sentido más originario (e histórico) antes que sean ańadidas las categorías y etiquetas de arte y obra. Además, muestran preocupación por aquellas manifestaciones visuales que, dentro de las disciplinas tradicionales, o instauradas al menos a la usanza tradicional, no tienen cabida como objetos de estudio. Aún más, el hecho de considerar ambos lados del problema de lo artístico como campo de estudio, podría hacer más patentes las similitudes y diferencias entre una imagen artística y una no artística, contribuyendo a una definición más precisa de arte a lo largo de la historia y aportando luces sobre el significado que este concepto tiene en un momento y en una sociedad determinada. De este modo los Estudios Visuales no convierten en obsoleto el concepto de estética ni los principios que se desprenden de ella, sino que los sitúa en un punto en el cual sea posible ver las diferentes clases de valor que les asignamos en el momento de escribir, además de poder entrever su aplicabilidad en otras regiones y situaciones (Moxey, 2006) como propuso Rampley, para ilustrar este punto. No podemos sino poner en evidencia que el juicio estético con que Occidente acostumbra mirar las imágenes creadas en una sociedad es un producto de la Ilustración que no tiene adecuación ni aplicación en otras culturas como los Baule de Costa de Marfil y los Abelam de América del Sur, solo por nombrar algunas (Rampley, 2006).

¿Qué representa hoy la estética para la Historia del Arte y los Estudios Visuales? Si la Historia del Arte ha de ser de nuevo filosófica, como propuso Ann Holly, tendría que partir del cuestionamiento no solo de lo que entendemos hoy por historia sino de lo que entendemos también por estética, poniendo atención en 
cómo los conceptos fundacionales de la disciplina se transforman según cada autor (Ann Holly, 2004). Se exige que reconsideremos el significado, o los significados, que usualmente atribuimos a estos conceptos que tenemos como eternos e inmutables, pero que son productos de una coyuntura histórica concreta, en un lugar preciso y una sociedad determinada y que rarísima vez son ellos los objetos de estudio. Cuando el filósofo francés Hubert Damisch planteó que el arte piensa ¿a qué se refiere? Evidentemente no al objeto por sí solo, no a la obra artística por sí misma, sino en tanto esta posee en algún sentido aquella conciencia de representación, tan cara a Diego Velázquez, que se ancla en la tradición moderna que concibe el arte como una forma de conocimiento crítico (Van Alpen, 2006), que permite entender el arte como un agente activo en la historia que, más allá de su particularidad histórica y su especificidad temporal y espacial, engendra cuestiones universales sobre las cuales no es solamente posible, sino que válido, realizarle preguntas. Es en este sentido en que las imágenes son autónomas, en tanto se constituye en un papel de agente activo en la sociedad más allá de su dependencia temática del contexto que lo rodea en su momento de creación y recepción. La imagen como un objeto desde donde podemos reflexionar en torno a la historia y, más ampliamente si cabe, en torno a la cultura. Un lugar desde el cual es válido cuestionar todo el hacer-historia, el hacer-mundo, campo de estudio mucho más amplio que el de la Historia del Arte y que los Estudios Visuales debiesen tomar con ánimo intelectual.

Del mismo modo, también podemos identificar otro fenómeno: entender las imágenes como objeto de reflexión es el propósito no solo de Damisch, sino que de la rama más actual de la Antropología del Arte. No considerar las imágenes solamente como un reflejo de una sociedad o época determinada sino como un acto de pensamiento, sobre el cual es posible reflexionar y desde el que se piensa el período que la originó, pues su significado solo puede ser formulado históricamente. La imagen como presencia, el arte como agente: es el punto de partida que tuvo el historiador del arte David Freedberg para sus análisis de la relación entre las imágenes y las personas a lo largo de la historia, tal como declaró en la introducción de su libro más famoso (El poder de las imágenes, 1989), que incluye conscientemente todas las imágenes y no solamente aquellas consideradas artísticas. La tensión entre lo universal y lo particular, entre la Historia y la Filosofía vuelve una vez más a estar presente al momento de considerar las imágenes y su función. Freedberg escribió: «llamaba poderosamente la atención las respuestas [a las imágenes] que se habían observado manifiestamente a lo largo de la historia y a través de las culturas, ya fueran "civilizadas" o "primitivas"» (2009, p. 29).

Una vez más, ahora desde la Antropología del Arte, la pretensión ilustrada del espectador de juicio estético desinteresado vuelve a ser puesto en cuestión y, eruditamente, rebatido. Que las imágenes a lo largo de la historia, aquí y en 
cualquier parte han provocado respuestas emocionales y sexuales y los sujetos lloran, se enojan, las rompen, las besan, viajan por ellas, es un hecho ya bastante probado (bien lo sabía el escritor francés Georges Bataille): "Hasta qué punto las imágenes podían ser eficaces y qué amplia gama de funciones tenían" escribe Freedberg (2009, p. 23).

En otro ejemplo, este el mismo punto de partida del análisis que hizo el historiador del arte Hans Belting, quien consideraó las imágenes como un agente activo en la sociedad, donde el funcionamiento de estas puede verse desde el enfoque humano y el artefacto técnico (Belting, 2010). El autor, al proponer un nuevo tipo de iconología, lo que hace es apuntar a establecer un puente entre la vida pasada y presente de las imágenes, pues el qué de una imagen está determinado por el cómo se transmite, que a su vez es en gran medida moldeado por el medio en el cual reside la imagen. Al igual que Regis Debray, el mediólogo francés, quien considera el medio de las imágenes un elemento crucial de su propio significado y esencia (Debray, 1994), tanto Belting como Freedberg lo que intentan es hacernos comprender que las imágenes no fueron creadas para lo que nosotros, hoy, en el siglo XXI, creemos que lo fueron. Sus causas de producción son muy alejadas de la estética que ha dominado nuestra forma de apreciación y estudio de las imágenes desde el momento mismo en que adoptamos la etiqueta de aquellas que son artísticas y aquellas que no lo son al momento de escribir su historia.

El acento en la vuelta hacia lo original, lo primero, lejos de ser una mera pretensión de acabar con los conceptos modernos heredados de la filosofía idealista, nos ponen de frente contra lo que las imágenes fueron en su propio momento de creación: utensilios, artefactos, artilugios, pero no obras (en su sentido moderno y actual), no al menos aquellas creadas antes del siglo XIX. Esta especificidad histórica, sin embargo, no contrasta para nada con aquello que Damish desde su posición nos quieren hacer entender: por más coyuntural y específica que sea la imagen que estudiamos, siempre podremos cuestionarla en torno a valores a-históricos, entendiendo lo a-histórico como aquello que trasciende su momento mismo de creación. Allí radica la doble verdad de la imagen: su significado solo puede ser entendido cuando volvemos al origen el cual, sin embargo, no nos impide entender la imagen como un acto de pensamiento que trasciende ese momento originario. La misma tensión entre lo particular y lo universal, entre lo global y lo local que propuso Bal al referirse a la problemática re-situación del concepto de cultura para construir un verdadero campo de estudio cuyo objeto sea una Cultura Visual. 


\section{CONCLUSIONES}

De esta forma, a partir de elementos tomados de la filosofía, antropología, estudios de género, estudios culturales, estudios postcoloniales y teoría crítica, los Estudios Visuales se entienden como un campo de estudios surgido desde la Historia del Arte, que se explican como una puesta en evidencia de sí misma, como un hacerse-saber, un hacerse-ver explícitamente sobre los conceptos con los que la Historia del Arte ha trabajado (y sigue haciéndolo). Los Estudios Visuales deben entenderse como un profundo desarrollo de autocrítica en donde aquellas categorías heredadas son re-situadas como aquello que originalmente fueron. En primer lugar, la inclusión del observador como un sujeto que otorga sentido a la imagen y sobre el cual esta tiene influencias de diversa índole y en distintos grados, independiente del tipo de sociedad en que se encuentre, muy lejos del espectador de contemplación estética desinteresada que la Historia del Arte ha asumido como el único estimable.

Se desprende desde aquí que incluso el acto mismo de mirar sea desautonomizado por los Estudios Visuales, exponiendo su carácter "impuro" y saturado de elementos externos a la visión misma (político). Segundo, la inclusión de imágenes "no artísticas" como un acercamiento al rol original que jugaron las imágenes que no fueron creadas para el salón o el museo ni para ser solamente contempladas y sobre las que se han impuesto las etiquetas modernas de «obra de arte». De esta forma, los Estudios Visuales tratan las imágenes con una fidelidad histórica mayor puesto que atienen su análisis a la particularidad histórica de las imágenes producidas sin perjuicio de cuestionamientos universales a partir de ellas. Finalmente, y lo más importante, los Estudios Visuales, al incluir las categorías enunciadas, renuncian explícitamente a seguir considerando como universales aquellos conceptos concebidos en momentos y lugares históricos precisos y que habían dominado la Historia del Arte hasta, al menos, la década de los ochenta. La mayor consecuencia a la hora de escribir sobre las imágenes, es que estos mismos conceptos pueden no ser solamente puestos a prueba, sino que es posible analizar la importancia que tuvieron en el momento mismo de escribir sobre ellos y con ellos. La metodología que debiesen asumir los Estudios Visuales, de esta manera, es la propia puesta en evidencia de las condiciones particulares que traman al investigador y la disciplina en que se inscribe, en el momento mismo en que escribe. Cuando la originalidad no significa otra cosa que volver al origen. 


\section{REFERENCIAS}

Alpers, Svetlana. El Arte de Describir. El Arte Holandés en el Siglo XVII. Madrid: Hermann Blume, 1987.

Alpers, Svetlana, Emily Apter \& Carol Armstrong, et al. "Visual Culture Questionnaire", October, 77/53 (1996): 25-70.

Ann Holly, Michael. "De vez en cuando", Estudios Visuales, 2 (2004): 63-68.

Bal, Mieke. "El esencialismo visual y el objeto de los Estudios Visuales", Estudios Visuales, 2 (2004): 11-49.

Brea, José Luis. "Estética, Historia del Arte, Estudios Visuales", Estudios Visuales, 3 (2006): 8-25.

Burke, Peter. Visto y no visto. El uso de la imagen como documento histórico. Barcelona: Crítica, 2005.

Crary, Jonathan. Las técnicas del observador. Visión y modernidad en el siglo XIX. Murcia: Cendeac, 2008.

De la Flor, Fernando."El impacto de los Visual Studies y la reordenación del campo de disciplinas del texto en nuestro tiempo", Hispanic Issues Online, 2 (2007): 65-78.

Déotte, Jean-Louis. ¿Qué es un aparato estético? Benjamin, Lyotard, Rancière. Santiago de Chile: Ediciones Metales Pesados, 2012.

Elkins, James. The Domain of Images. Nueva York: Ithaca,1999.

Freedberg, David. El poder de las imágenes. Estudios sobre la Historia y la teoría de la respuesta. Madrid: Cátedra, 2009.

García, Rafael. Iconografía e Iconología. Cuestiones de método. Vol. II. Madrid: Encuentro, 2009.

Hernández, Fernando. “¿De qué hablamos cuando hablamos de cultura visual”, Educação \& Realidade, 34 (2005): 9-34. 
Leech, Peter. "La cultura visual y la ideología de lo sublime", Estudios Visuales (2004): 69-75.

Mitchell, William. "Mostrando el ver: una crítica de la cultura visual", Revista de Estudios Visuales, 1 (2003): 18-40.

Moxey, Keith. "Estudios Visuales, Historiografía y Estética”, Estudios Visuales, 3 (1996): 99-124.

Moxey, Keith. "Los Estudios Visuales y el giro icónico", Estudios Visuales, 6 (2009): $8-26$.

Palos, Joan Lluís. "El testimonio de las imágenes”, Revista Pedralbes, 20 (2000):127142.

Rampley, Matthew. "La Cultura Visual en la era postcolonial: el desafío de la antropología”, Estudios Visuales, 3 (2006): 186-211.

Van Alpen, Ernst. "¿Qué Historia, ¿la Historia de quién, Historia con qué propósito?: Nociones de Historia en Historia del Arte y Estudios de Cultura Visual", Estudios Visuales, 3 (2006): 80-97. 